\title{
ASSESSMENT OF PREDICTIVE VALIDITY OF COLLEGE ENTRANCE EXAMINATION QUESTIONS (CEEQ) FOR 2014/2015 ACADEMIC SESSION AT BAYELSA STATE COLLEGE OF HEALTH TECHNOLOGY, OGBIA
}

\author{
Memory Queensoap*, Ph.D \\ Department of Arts Education, \\ Faculty of Education, \\ Federal University Otueke
}

\author{
Theresa Baikwe Osusu \\ Department of Arts Education, \\ Faculty of Education, \\ Federal University Otueke
}

Article DOI: https://doi.org/10.36713/epra5999

\begin{abstract}
Every test designed for purposes of admission is expected to possess psychometric properties of a test in order to address the social implications of tests. This study was aimed to determine the predictive validity of College Entrance Examination Questions (CEEQ) for 2014/2015 academic session. An expos-facto research design was used on a sample of 105 candidate entrance scores and Cumulative Grade Point Averages (CGPA) from seven programs of study. Data were obtained from the College Registry and various departments running the programs. Data collected were analyzed, using Microsoft Excel 2010 and Statistical Package for Social Sciences (SPSS) 20. Result of analysis showed that CEEQ score could predict students' CGPA by $2.8 \%$ only. It was also determined that CEEQ has a weak but positive relationship with CGPAs (16.7\%). On running the data on simple regression statistics revealed that the CEEQ do not predict CGPAs significantly as $p=.089$ $(P>.05)$. It was concluded that CEEQ was not valid hence recommendation was made that College management should look forward to develop a standardized test for admission purposes.
\end{abstract}

KEY WORDS: Psychometric properties, predictive validity, questions, test, entrance, academic performance.

\section{INTRODUCTION}

Generally, every institution in the world, especially higher institutions admits students at least yearly at undergraduate and post-graduate levels. Admissions into the institution are based on specified criteria either set by the legislation from the government or by the institutions.

Any testing system in education, such as that for Universities or College admissions, will inevitably have an impact on other areas of the educational process, as well as having broader social consequences. Considerable debate has centered on the effects of admissions testing in the United States, and what the positive and negative consequences of these are (Anastasi \& Urbina, 2005).

In Nigeria, the levels of education the Nigerian child is expected to pass through; depending on performance and interest are distinctly specified. The education policy document gave provision for early Childhood/Pre-primary Education which consist of crèche, the nursery and the kindergarten, Basic Education that shall be of 9-year duration comprising 6 years of Primary Education and 3 years of Junior Secondary Education; Secondary Education which is an education children receive after primary education and before the tertiary stage(Federal Republic of Nigeria, 2004).The policy document provided continuing education option through vocational and technical school. More so, those that are willing to proceed with their academic pursuit are provided with the tertiary sector which consisted of a university sector and nonuniversity sector. The latter is made up of Polytechnics, Monotechnics, Colleges of Education and Colleges of Health Technology. 
Nevertheless, entry requirement into the first degree program of Nigerian institution of higher learning is based on possession of required credit passes in subjects relevant to students proposed course of study in the Secondary School Certificate Examination (SSCE) or its equivalent conducted by West African Examination Council (WAEC) or National Examination Council (NECO); the Unified Tertiary Matriculation Examination (UTME) and attainment of the minimum age of 16 years(Olawaiye \& Oluwaseun, 2014). These admission criteria into higher institution in Nigeria are stipulated by the National Universities Commission (NUC). The minimum marks required on the UTME for admission to universities is 200 (out of 400) while 150 and above for Colleges of Education, Polytechnics and Monotechnics (Olawaiye \& Oluwaseun, 2014). However, each institution has cut of marks for various programs, so minimum of 150 marks does not guarantee admission (Onyukwu, 2011).Universities also conduct additional screening before final admission decision is made. Screening exercises, understandably, are done to ensure quality of products (Onyukwu, 2011) thereby introducing aptitude tests.

Unlike the circular universities and colleges in Nigeria, the College of Health Technology, Otuogidi, Ogbia-Town based admission of students in three facets namely WAEC/NECO (SSCE)/good honors degree, Entrance Examination and Probation Examination which all students must meet up to the standard set up. To be explicit, the SSCE certificate is obtained at the secondary level and individual program require specific order of credit passes on specified subjects which students must possess before entering for the Entrance Examination. The entrance examination is conducted by the registry. This examination usually takes one (1) hour or less (depending on the number of items that will make up the test) with question items consisting Uses of English language, Mathematics and Current affairs/or general sciences. At the end, successful candidates are short listed for the admission into the Probation Program. All these are geared toward maintaining a standard.

The main objective of the admission system is to determine candidates who would likely do well in the College. The quality of candidates admitted into any higher institution affects the level of research and training within the institution, and by extension, has an overall effect on the development of the country itself, as these candidates eventually become key players in the affairs of the country in all sectors, especially on human health.

Psychological journals are full of papers about predictors of academic performance of university psychology students. This is in contrast with other specialties, especially technical/professional ones like College of Health Technology. To bridge the gap in health training institutions, the present study was to assess the predictive validity of the College Entrance Examination Questions (CEEQ) of the Bayelsa State College of Heath Technology, Otuogidi, Ogbia-Town.

\section{OVERVIEW OF TEST AND ITS PSYCHOMETRIC PROPERTIES}

The most common place of the ordinary usage of the word, 'Test' is to assess the degree to which the terminal behavior of a student differs from their initial behavior. Consequent upon this, there are many testmakers who have given seemingly insoluble definitions of test. That is, contextual differences may occur but they all tune into one meaning. For (Egbule, 2007), a test is any kind of device or procedure for measurement of aptitude, interest, ability, achievement and any other traits or personal attributes. Similarly, (Onunkwo, 2005) defined a test as a measurement device used to quantify behavior or aid in understanding and predicting behavior. (Ubulom, Uzoeshi, Amini, \& Vipene, 2019), considered test as the instrument or tool adopted in obtaining data or information relating to an individuals' qualities.

In view of these definitions, a test is an instrument or tool used to determine the presence or absence of a trait, attitude, characteristic, behavior etc. in an individual or about an object or thing. This view does not restrict test to the common place definition of test as question set for student in the classroom. It transcends beyond this and thus is referred to as psychological testing. In all definitions, psychological tests are identified as tools which play a significant role, especially standardized tests in measurement of behavior. Test, undoubtedly, helps in the area of classroom instruction, guidance, administrative, individual and research (Ubulom, et al., 2019).

Following this fact, psychological tests possess certain qualities which are called psychometric properties. Any instrument possessing these psychometric properties are considered as good tests. Egbule (2007) reiterated that for a test to be known, as appropriate for measuring anything, such a test must possess certain desirable psychometric properties. Consequently, (Onunkwo, 2002) and (Ukwuije, 1996), identified psychometric properties of psychological test as validity, reliability and usability. Validity, according to Onunkwo (2005), is the degree to which an instrument measures the qualities, abilities, skills, traits, and information etc. it was designed to measure. For instance, statistic examination test (SET) designed to measure students' knowledge or ability on statistic, is 
only valid if it measures the students' knowledge or ability in statistics and nothing but that. (Anastasi \& Urbina, 1997), stated that validity provides a direct check on how well the test fulfills its function. The determination of validity usually requires independent, external criteria of whatever the test is designed to measure.

In a similar perspective, Ukwuije (1996) asserted that "a test that has high validity for one purpose may have moderate validity for another and negligible validity for a third"(p.108). This assertion supported the view that there is no hard and fast rule for deciding what is meant by high validity, moderate validity or low validity. Ukwuije further stressed that skills in making such judgment came only through training and experience in dealing with test. The expertise in making judgment lies with the psychometrics. Onunkwo (2005) and Ukwuije (1996) provided four main types of validity as;

* Face validity meaning a superficial examination of the instrument,

* Content validity showed how well the instrument measures the subject matter or content.

* Criterion-related validity indicated how well the instrument predicts values or measures future performance. It occurs in two forms; predictive and concurrent validity.

* Construct validity indicated that the instrument measures performance related to a popular, construct or psychological quality.

Reliability, as earlier pointed out, is another indispensable quality of a good test or instrument. Onunkwo (2002) maintained that reliability is the degree to which measurements are free from random influence. That is, reliable instrument should not be susceptible to unrealistic influences. This suggests that such test should show similar outcome anywhere anytime being administered and scored. Onunkwo said that reliability coefficients can be obtained by several methods. Each type has somewhat different meaning. These include:

* Alternate form reliability method measuring coefficient of equivalent or temporal stability of an instrument depending on how the two tests were administered.

* Test Retest approach is administered to the same group of students on two different occasions which aims at measuring coefficient of stability.

* Split half, Kuder-Richardson (either 20 or 21), Cronbach's Alpha are distinctly different techniques in measuring coefficient of internal consistencies.

The degree to which a test can be successfully employed by classroom teachers and administrators without an undue expenditure of time, energy and money is referred to as usability. This is another relevant psychometric property a good instrument should possess. Usability is the practicality of the test or instrument. Onunkwo (2002) highlighted the practical consideration that determine the usability of an instrument as economy, ease of administration, duration of instrument, ease of scoring and ease of interpretation. Similarly, Ubolum et al., (2019) added that for a test to have the property of employability (usability), among other characteristics should have practical considerations such as availability of equivalent form of test, simplicity of instruction, etc. Therefore, for a test to be considered good it has to measure what it claims to measure (validity), measure it consistently (reliability) and with minimum expenditure of time, energy and money (usability). These three psychometric properties of test are most instructive against the College Entrance Examination Questions (CEEQ) which was prepared purposely to screen candidates into the College.

\section{ENTRY GRADE AND STUDENTS' ACADEMIC PERFORMANCE}

Academic success is no doubt the main focus of all academic activities. Academic is concerned with studying especially at college or university level. Success is defined as when one achieves what he/she wants or intends. This implies to the study that academic success denotes achievement in the course or at the end of a study at a college or university level by a student. Academic success can as well means performance or achievement. That is to say academic achievement refers to grade in report cards used at the end of a period indicating to student their performance in various academic subjects.

To some authors academic achievement is the outcome of education-the extent to which a student, teacher or institution has achieved their educational goal. That is to say, academic performance in educational institutions as a success measured by how well a student meets standards set out by the institution. This definition points to the student being awarded in character and in learning at the end of the program of study.

Available literatures argued that there is no general agreement on how academic achievement is best tested or which aspects are most important, that is, procedural knowledge (skill) or declarative knowledge (facts). This opinion can be interpreted that there is no 
fast and hard rule about measurement of students' academic achievement or success. A student can be measured by either examination or continuous assessment or both. The performance of student is translated as Cumulative Grade Point Average (CGPA) or Simple Average depending on the type of program and institution of study. Nevertheless, entry grade such as SSCE (WAEC/NECO), UME, PUME, Entrance, etc. are used as preadmission criteria in the higher institution. For the Bayelsa State College of Health Technology, SSCE, Entrance and Probation Examination are used. Do these entry grades predict the student's success? Many varied findings on the relationship of the various entry qualifications in higher institutions have been advocated by various researchers. Empirical studies reported very low significant relationship between the University and Tertiary Matriculation Examination (UTME) scores and CGPA value at all levels. SSCE as an entry grade showed much reliability to predict academic success than UTME (Olawaiye \& Oluwaseun, 2014). Similarly, a positive but a low relationship between CGPA and other admission qualifications such as SSCE and UTME was observed (Ajogbeje \& Borisade, 2013).

The relationship between entry grade and graduate performance has not been consistent depending on the specific indicators used for success in graduate or under graduate education as well as type of program. They further stated that in cases where statistical significant correlation is found, the correlation is a weak one, that is, between $0.24-0.38$ (Alias \& Zain, 2006.). A low correlation coefficient (0.1751) between CGPA and UME results, moderate correlation (0.6740) between CGPA and National Certificate in Education (NCE) results and also moderate correlation (0.4120) between CGPA and SSCE were reported. This later finding between SSCE and CGPA was in line with finding of WAEC which identified a positive and significant relationship between candidates' performance in the SSCE and academic performance in the university undergraduate level, however, the writer argued that there is a very low correlation between SSCE and academic performance of university undergraduates (Queensoap, Arogo, Memory, Ogbari, \& James, 2017).

This is a clear indication that works on relationship between entry qualification and academic performance is revealing seemingly insoluble findings. Nevertheless, based on his findings recommended that, there is need to make, NCE, National Diploma (ND) and their equivalents the basic qualification for admission of candidates into undergraduates programs in Nigerian to complement the admission of candidates with good and genuine SSCE and UME results.
Adopting this recommendation may improve the quality of academic performance of students in Nigerian higher institutions (Gbore, 2013.).

Entry qualifications, previous academic performance and gender could predict academic performance of the students in the nursing diploma program (Ali, 2008.). The author further concluded that the academic factors considered in the admission criteria could predict the subsequent academic performance of the nursing students in the general nursing diploma program.

\section{OVERVIEW OF PREDICTIVE VALIDITY}

In science and statistics, validity is the extent to which a concept (Brains \& Manhem, 2011), conclusion or measurement is well-founded and corresponds accurately to the real world. Validity of a measurement tool is considered to be the degree to which the tool measures what it supposed to measure. In psychometrics, validity has a particular application known as test validity which means "the degree to which evidence and theory support the interpretations of test scores" (American Educational Research Association, 1999 ). Meanwhile, in the area of scientific design and experimentation, validity refers to whether a study is able to scientifically answer the questions it is intended to answer. There are different ways in determining the validity of an instrument or test. The common types of validity that are used in validating an instrument or test include face-value validity, content validity, construct validity and predictive validity (Ayandokun, 2014.).

Amongst other types of validity, the main concern of this paper is predictive validity. Predictive validity refers, in simple term, to as the extent to which an instrument can predict future performance (Ayandokun, 2014). This denotes that predictive validity is described when any measurement predicts a relationship between what is measured and something else, predicting whether or not the other thing will happen in the future. In psychometrics, as earlier considered, predictive validity is the extent to which a score on a scale or test predicts scores on some criterion measure.

In a strict study of predictive validity, the test scores are collected first; then at some later time the criterion measure is collected. Predictive validity provides somewhat more useful data about test validity because it has greater fidelity to the real situation in which the test will be used. Most educational and employment tests are used to predict future performance, so predictive is regarded as essential in this area (Shuttleworth, 2009.). 


\section{PREDICTIVE VALIDITY AND SELECTION EXAMINATION}

The most common use for predictive validity is inherent in the process of selection students for university, college and other higher institutions. Most institutions use high score to decide which students to accept or admit in an attempt to find the capable ones to run the programmes available (Shuttleworth, 2009). Quite literally, there have been hundreds of studies testing the predictive validity at this instance of using entrance score to predict future performance of students.

To achieve this, researcher takes the grades achieved after the first year of studies and compare with the entrance scores (Shuttleworth, 2009). A high correlation indicates that the selection procedure worked perfectly, a low correlation signifies that there is something wrong with the approach. Most of the studies showed that there is a strong correlation between the two, and the predictive validity of the method is high, although not perfect (Shuttleworth, 2009).

Another study (Ali, 2008), examines the predictive ability of the performance of medical students during the first trimester from their admission scores. Findings showed a significant relationship between admission test scores and subject test scores in MBBS Part 1 examination. This implies that there is a relationship between entry grades and academic performances. In a similar vein, it was established that High-School Grade Point Average (HSGPA) is consistently the best predictor not only of freshman grades in college, the outcome indicate most system employed in predictive validity studies, but of four-year outcome as well (Geiser \& Santelices, 2007).

Again it was stated that several studies have found that high school grades are more accurately predicting academic achievement than any other factor. Similarly, it has been observed that secondary grades served as good predictors for academic performance. Secondary school grades proved to be an important selection criterion, although different views have been presented about their relationship in other literatures asserted that High School Grade Point Average predicted academic success (CGPA) of the Allied health group as a whole and should be used as part of the process of admission in higher education until such time that more predictive criteria are determined (Hoffman \& Lowitzki, 2005). There exist, therefore, a connection between entry grade, whatever case it may be called, with students performance in their educational endeavor.

Nevertheless, some writers asserted that some criteria used for admission into the college or university did not serve the predictive purpose for which they were intended hence concludes that academic predictability is perhaps generally situational. They added that Educational research literature is replete with findings which indicate that academic achievement is apparently difficult to predict due to too many factors operating upon the learner. It was highlighted that there are extraneous factors that are responsible for the difficulty to predict academic success with entry grades. Such factor they presented as method of teaching, lecture hours, academic and residential environments (Hoffman \& Lowitzki, 2005). Variables like learning preference, age, gender, and entry qualification are some factors that affect academic performance of students in higher institution however, more determinants of academic performance need to be investigated.

\section{METHODOLOGY}

This research work adopted a correlation research design. The design enabled researcher to investigate the possibility of relationship between college entrance score and students cumulative grade point average (CGPA) without influencing or manipulating any of the variables. 105 students were sampled through systematic random sampling technique. Records of entrance scores and their corresponding cumulative grade point average were obtained from the registry (exams and record department) of the College. These are classified and confidential records of students. The entrance scores and the cumulative grade point average of the students were obtained after certifying ethical condition of the college research ethical committee. Descriptive statistics (mean and standard deviation), correlation and regression statistics were employed to analyze data and test the null hypothesis at .05, alpha level of significance. Statistical Package for Social Sciences (SPSS) 20 was used as software to aid the analysis.

\section{RESULTS}

Research Question 1: To what extent does Entrance Examination Questions (CEEQ) of 2014/2015 academic session has predictive validity? 
Table 1: Summary Model of Regression Analysis

\begin{tabular}{lllll}
\hline Model & $\mathbf{R}$ & R Square & Adjusted R $\mathbf{R}^{2}$ & $\begin{array}{l}\text { Standard } \\
\text { Estimates }\end{array}$ \\
\hline $\mathbf{1}$ & .167 & .028 & .018 & 13.60 \\
\hline
\end{tabular}

Table 1 above has indicated that $\mathrm{R}$ is $.167, \mathrm{R}^{2}$ is .028 , Adjusted $\mathrm{R}^{2}$ is .018 while standard error of estimate is 13.60. Based on the $\mathrm{R}^{2}(.028)$, it can be deduced that the coefficient of determination is $2.8 \%$ $(.028 \mathrm{x}$ 100). It implies therefore, the entrance examination scores can only predict student cumulative grade point average by $2.8 \%$ which is low.

Research Question 2: To what extent do candidates' entrance scores correlate with their cumulative grade point average after admission?

Table 2: Summary of Descriptive and Correlation Statistics

\begin{tabular}{llllllll}
\hline Variables & $\mathbf{N}$ & Mean & Std Dev. & Pearson $\mathbf{r}$ & $\boldsymbol{P}$ val. & $\begin{array}{l}\text { Chosen } \\
\boldsymbol{\alpha}(\mathbf{1}- \\
\text { tailed })\end{array}$ & Decision \\
\hline CGPA & 105 & $6.59^{*}$ & 13.74 & & & & \\
$\begin{array}{l}\text { Entrance } \\
\text { Scores }\end{array}$ & 105 & 15.39 & 2.69 & .167 & .044 & .05 & Reject $\mathrm{H}_{0}$ \\
\hline
\end{tabular}

*CGPA Value is influenced by Average Score from Pharm Tech

Table 2 showed number of respondents $(\mathrm{N})$ as 105, mean and standard deviation for CGPA and Entrance score as $6.59 \pm 13.74$ and $15.39 \pm 2.69$ respectively. Table 2 also was observed showing a Pearson correlation coefficient between the predictor (Entrance score) and criterion (CGPA) variables as .167 with a $P$ value of .044 at .05 , chosen alpha level of significance (1-tailed). Therefore, since $P$ value is less than .05, the null hypothesis of no significant relationship is rejected. It means that there is a statistically significant relationship between the entrance scores and the corresponding CGPAs.

Research Hypothesis 1: Students' college entrance examination scores do not significantly predict their cumulative grade point average.

Table 3: Testing the significance of level of prediction of Entrance Scores on CGPA

\begin{tabular}{|c|c|c|c|c|c|c|}
\hline Variables & B & Beta $(\beta)$ & $\mathbf{T}$ & Sig. & $\mathbf{A}$ & Decision \\
\hline $\begin{array}{l}\text { Entrance } \\
\text { Scores } \\
\text { CGPA }\end{array}$ & .853 & .167 & 1.718 & .089 & .05 & Accept $\mathrm{H}_{0}$ \\
\hline
\end{tabular}

Table 3 has shown un-standardized regression coefficient (B) of .853, indicating that for every 1 unit increase in entrance score, there is an increase of .0853 in CGPA. The standardized regression coefficient (Beta or $\beta$ ) is .167. The $\beta$ of .167 is not significant at .05 as $P$ value (Sig.) is .089. Therefore, since the $\beta=.089, p$ $>.05$, two tailed, the null hypothesis of Students' college entrance examination scores do not significantly predict their cumulative grade point average is not rejected. That is, the entrance scores were not able to predict the criterion variable (CGPA) significantly.

\section{DISCUSSION}

This present study aimed at assessing the predictive validity of the College Entrance Examination Questions (CEEQ) of 2014/2015 academic session at
College of Health Technology, Otuogidi, Ogbia-Town. It was observed that $54 \%$ of the candidates who attempted the College Entrance Examination Questions score between 10-15 while 41\% scored 16-20 marks. The paper was dichotomously scored with a maximum mark point of 25 . This showed that many succeeded in the entrance examination. Consequently, their cumulative grade point average (CGPA) showed similar score profile where $46 \%$ obtained $3.00-3.59$, relating a good performance.

The study observed that there is a significant relationship between the entrance scores and the CGPAs of the students, however this was a weak relationship $(\mathrm{r}=.167 \mathrm{r} 16.7 \%)$. This finding was in line with Ali (2008) whose findings showed a significant relationship between admission test scores and subject test scores in MBBS Part 1 examination. This implies 
that there is a relationship between entrance score and students' academic performances.

The relationship between entry grade and graduate performance has not been consistent depending on the specific indicators used for success in graduate or under graduate education as well as type of program. They further stated that in cases where statistical significant correlation is found, the correlation is a weak one, that is, between $0.24-0.38$ (Alias \& Zain, 2013). A low correlation coefficient (0.1751) between CGPA and UME results, moderate correlation (0.6740) between CGPA and National Certificate in Education (NCE) results and also moderate correlation (0.4120) between CGPA and SSCE were reported. These findings support the finding of this study because the correlation coefficient was .167 or $16.7 \%$ which of course was weak relationship.

Consequently, the study observed that the entrance score predicted the CGPAs to an extent of $2.8 \%$. Does this prediction statistically significant? The study determined that there was no significance as $\mathrm{p}=$ .089 ( $>$ >.05). This implies that the CEEQ was not valid. Some studies had affirmed that entry grade, whatever it may be called, had high predictive validity (Shurttleworth, 2009; Geiser \& Santelices, 2007; Hoffman \& Lowitzki, 2005). It means therefore that the entrance score which is an entry grade for admission was low hence it has not measured what it was actually designed to measure.

\section{CONCLUSION}

Based on the far reaching findings determined at course of the study, the study held that CEEQ was not a valid test/examination paper. The items never measured what they were constructed to measure. A test used for admission is expected to predict the outcome of the student after admission. CEEQ showed a weak relationship, though positive, with students CGPAs and was able to predict with insignificant level of $2.8 \%$. There is a need to look into how entrance examination questions are being set.

\section{RECOMMENDATIONS}

The study unequivocally proffered the following recommendations as drawn from the findings and conclusion of the study.

* College management should look forward to develop a standardized college entrance examination questions that will serve admission purposes.

* Alternatively, examination bodies such as NECO, WAEC, etc. could be consulted to assist in examining candidates for admission.

* Colleges of Health Technology in Nigeria should look forward to propose a Unified College of Health Technology Examination Board to take charge of conducting entrance into the Colleges.

\section{REFERENCES}

1. Ajogbeje, O. J., \& Borisade, F. T. (2013). Cognitive Entry Characteristics and Semester Examination Scores as Correlates of College Students' Achievement in Mathematics. British Journal of education, society \& Behavioural science, 3 , 478489.

2. Ali, P. A. (2008.). Admission Criteria and Subsequent Academic Performance of General Nursing

3. Diploma Students. Journal of Pakistan Medical Association.2.

4. Alias, M., \& Zain, A. F. ( 2006.). Relationship between Entry Qualifications and Performances in Graduate Education. International Education Journal, 7 , 18-29.

5. American Educational Research Association. (1999 ). Standards for Educational and Psychological Testing . Washington, DC: American Educational Research Association.

6. Anastasi, A., \& Urbina, S. (1997). Psychological Testing. India: Prentice - Hall.

7. Ayandokun, O. E. (2014.). A Guide to Effective Study, Research and Documentation rev.ed. Lagos: Gloryline Christian Publications.

8. Brains, W., \& Manhem, R. ( 2011). Empirical Political Analysis 8th ed. Boston, MA: Longman.

9. Egbule, J. (2007). Principles of psychological testing (Rev. ed.). Lagos: Functional Publishing.

10. Federal Republic of Nigeria. (2004). National Policy on Education 4th edition. Lagos: Federal Ministry of Education .

11. Gbore, L. O. (2013.). Relationship between Cognitive Entry Characteristics and the Academic Performance of University Undergraduates in South West, Nigeria. Journal of Educational and Social Research, 3. doi:10.5901/jers .

12. Hoffman, J. L., \& Lowitzki, K. L. (2005). Predicting college success with high school grades and test scores, limitations for monitoring students. The Review of Higher Education, 28, 45-53.

13. Olawaiye, L. Y., \& Oluwaseun, A. S. (2014). Evaluation of the the admission characteristics that predict stdudents' final year academic performance: Abuad experience. Journal of Educational and Social Research, 4, DOI:10.5901/jesr. , 50-54.

14. Onunkwo, G. (2005). Tests: types, preparation, administration, communication. . Onitsha: VIGO Publishers. 
15. Onyukwu, J. (2011). The educational system of Nigeria. World Education and Reviews, 24.

16. Orluwene, G. W. (2004). Latent trait theory: models, estimation of parameters, and

17. application.Unpublished Doctoral Seminar paper. Port Harcourt.: University of Port Harcourt.

18. Queensoap, M., Arogo, N. I., Memory, D., Ogbari, D. W., \& James, D. M. (2017). Use of entry graade to predict Bayelsa State students' accademic success at College of Health Technology, Ogbia. International Journal of Education and evaluation, 74-84.

19. Shuttleworth, M. ( 2009., July 08). Predictive Validity Explorable.com. Retrieved from Explorable.com.:

20. Explorable.com: https//explorable.com/predictivevalidity.

21. Ubulom, W. J., Uzoeshi, K. C., Amini, C. M., \& Vipene, J. B. (2019). Fundamentals of measurement \& evaluation. Port Harcourt: Celwil Nigeria Limited.

22. Ukwuije, R. (1996). Test and measurement for teachers. Port Harcourt: Abe. 